\title{
Low-Temperature Plasma Exfoliated N-Doped Graphene for Symmetrical Electrode Supercapacitors
}

\author{
Keliang Wang ${ }^{\mathrm{a}}$, Ming Xu ${ }^{\mathrm{d}}$, Yan $\mathrm{Gu}^{\mathrm{e}}$, Zhengrong Gu${ }^{* a}$, Jun Liu ${ }^{* \mathrm{~b}}$, Qi Hua Fan ${ }^{* c}$ \\ a Agricultural and Biosystems Engineering Department, South Dakota State University, Brookings, SD 57007, United States \\ b Energy Processes and Materials Division, Pacific Northwest National Laboratory, Richland, WA 99352, United States \\ c Electrical Engineering and Computer Engineering, Chemical Engineering and Materials Science Department, Michigan State University \\ East Lansing, MI 48824, United States \\ d PetroChina Lanzhou Petrochemical Company, Lanzhou, Gansu, 730060, China \\ e Institute of Chemical Industry of Forest Products, Nanjing, Jiangsu, 21000, China
}

\section{Abstract}

Radio frequency (RF) dielectric barrier discharge plasma was used to exfoliate graphite oxide (GO) into graphene. The GO was synthesized from a modified Hummers method. The exfoliation occurred swiftly once the RF power and gas pressure reached a level that enabled sufficient energy transfer from the plasma to the GO. X-ray diffraction (XRD) and transmission electron microscopy (TEM) confirmed that graphene or carbon nanosheets were successfully prepared. The plasma exfoliation mechanism was revealed based on the microstructure characterization and optical emission spectroscopy, which indicated that oxygen was released at the moment of exfoliation. Inspired by the success of GO exfoliation, N-doping was realized by treating polypyrrole-modified GO with plasmas. The $\mathrm{N}$ concentration in the resulted graphene depended strongly on the plasma gas. Of the gases studied, $\mathrm{CH}_{4}$ treated polypyrrole-modified

\footnotetext{
${ }^{\text {a }}$ Z R. Gu Tel./fax: + 1605688 5372. Email address: zhengrong.gu@ @dstate.edu (Z. R. Gu)

b J. Liu Tel./fax: + 1509 375-4443. Email address: jun.liu@ @nnl.gov (J. Liu)

${ }^{c}$ Q H. Fan Tel./fax: + 1605 688-5910. Email address: qfan@egr.msu.edu (Q. H. Fan)
} 
$24 \mathrm{GO}\left(\mathrm{GO}-\mathrm{PPY}-\mathrm{CH}_{4}\right)$ contained considerable concentration of $\mathrm{N}$ that was beneficial to electrical 25 double layer capacitors (EDLCs). Supercapacitors made of the N-doped graphene exhibited

26 promising capacitive characteristics. Electrochemical measurements showed that the GO-PPY-

$27 \mathrm{CH}_{4}$ presented an initial specific capacitance of $\sim 312 \mathrm{~F} \mathrm{~g}^{-1}$ under $0.1 \mathrm{~A} \mathrm{~g}^{-1}$ charge/discharge current and $\sim 100 \%$ retention after 1000 consecutive cycles under currents ranging from 0.1 to $10.0 \mathrm{~A} \mathrm{~g}^{-1}$ in $6 \mathrm{~mol} \mathrm{~L}^{-1} \mathrm{KOH}$ electrolyte. This study demonstrated that the plasma exfoliation was an efficient approach to fabricating graphene and $\mathrm{N}$-doped graphene that had promising potential to be high-performance electrode materials for EDLCs.

Keywords: plasma, graphene, exfoliation, N-doped, supercapacitor

\section{Introduction}

Supercapacitors are electrical-energy-storage devices that have recently attracted considerable interest due to their long life cycle, fast charge/discharge capability, and high power [1-4]. Based on the working principles, supercapacitors can be classified into two major types:

37 pseudocapacitors and electrical double layer capacitors (EDLCs). In pseudocapacitors, fast redox reactions, also known as faradic reactions, occur between the electrode and electrolyte during charge/discharge. Subsequently electrical energy is stored[5]. Thus, metal oxides (e.g. $\mathrm{MnO}_{2}$, $\left.\mathrm{NiO}, \mathrm{Ni}(\mathrm{OH})_{2}, \mathrm{Co}_{3} \mathrm{O}_{4[6-9]}\right)$ are commonly used as the electrode materials to enable the redox

41 reactions with the electrolyte. In contrast to pseudocapacitors, no chemical reaction is involved 42 in EDLCs and carbon materials are commonly used for the electrodes. Energy storage in EDLCs 43 is achieved via adsorption and desorption of electrolyte ions. In this process, charge 44 accumulation occurs due to electrostatic attraction between the positive and negative charges that 45 separately reside at the electrode/electrolyte interface[10]. Pseduocapacitors have been 46 demonstrated with very high capacitive performance. However, their capacity usually decreased 
47 sharply with increasing cycles, especially at high current densities. On the other hand, EDLCs

48 possess superior stability under a wide range of current densities and excellent tolerance to a

49 broad variety of electrolytes, due to the inherent stability of carbon materials. In the past few 50 years, a variety of carbon materials (e.g. carbon nanotubes, carbon fibers, activated carbon and 51 graphene [11-14]) have been investigated as the electrodes for EDLCs. The desired 52 characteristics for the carbon electrode materials include[15]: i) high specific surface area (SSA) 53 to provide large accessible area to the electrolyte; ii) low resistance to minimize energy loss; iii)

54 suitable pore size to allow fast transfer of electrolyte ions; and iv) sustainable and abundant to 55 keep the cost low. These requirements have driven the research for various porous carbon and 56 carbon nanomaterials for high-performance supercapacitors. Current challenges that limit the 57 capacitive performance of porous-carbon-based electrodes include relatively low conductivity 58 and structural degradation due to swelling and shrinkage during the charge/discharge process. 59 Among the reported carbon materials, graphene has showed extraordinary potential for EDLCs 60 [16-18].

61 Graphene is a two dimensional $s p^{2}$ hybridized carbon layer that has proven excellent properties 62 including mechanical flexibility (high Young`s modulus 1.0 TPa) [19], exceptional thermal 63 conductivity $\left(5,000 \mathrm{~W} \mathrm{~m}^{-1} \mathrm{k}^{-1}\right)$ [20], high electrical conductivity $\left(\sim 10^{6} \mathrm{~S} \mathrm{~cm}^{-2}\right)[21]$, high 64 theoretical surface area $\left(2,630 \mathrm{~m}^{2} \mathrm{~g}^{-1}\right.$ for single layer graphene) [22], and high transmittance $65(97.7 \%)$ [23] to visible light. These unique physical and chemical properties make graphene 66 promising for many applications, such as energy storage and conversion (supercapacitors, fuel 67 cells, solar cells and Li-ion batteries) [24-27], biomedical technologies (biosensors and drug 68 carriers) [28, 29], and electronic components [30]. 
Many methods have been reported to fabricate graphene. In 2004, Geim and coworkers reported a scotch-tape method, in which graphene was prepared via mechanical exfoliation of graphite [31]. In 2006, planar carbon with a few layers of graphene was grown by chemical vapor deposition [32]. In 2007, epitaxial growth of graphene on SiC was reported [33]. In 2009, graphene was prepared via chemical exfoliation [34]. Of these methods, Hummers-method [35]based chemical exfoliation was easier to implement than the others. In Hummers approach, concentrated sulfuric acid $\left(\mathrm{H}_{2} \mathrm{SO}_{4}\right)$, sodium nitrite $\left(\mathrm{NaNO}_{3}\right)$ and potassium permanganate $\left(\mathrm{KMnO}_{4}\right)$ were used to exfoliate graphite flake to graphite oxides (GOs) and subsequently graphene was obtained via further chemical reduction and physical treatment.

The electrochemical properties of graphene could be modified by doping. Several groups have demonstrated N-doping that greatly promoted the specific capacitance of graphene. In 2011, Choi and Yang $[36,37]$ reported N-doped graphene prepared via plasma enhanced chemical vapor deposition and thermal nitridation, respectively. They prepared EDLCs using the N-doped graphene electrodes and obtained specific capacitance of 280 and $144.9 \mathrm{~F} \mathrm{~g}^{-1}$. In 2012 , specific capacitance of $245.9 \mathrm{~F} \mathrm{~g}^{-1}$ was reported by Chen [36] who used pyrolysis to prepare N-doped graphene. In 2013, Chen and Yang [38, 39] developed a solvothermal method to prepare Ndoped graphene and achieved specific capacitance of $301 \mathrm{~F} \mathrm{~g}^{-1}$. In 2015, Gomes [40] reported a simple thermal treatment method to prepare $\mathrm{N}$-doped graphene and attained a specific capacitance of $210 \mathrm{~F} \mathrm{~g}^{-1}$. However, all the above processes required high temperatures and were time consuming.

The demands for graphene and $\mathrm{N}$-doped graphene have driven the research on efficient fabrication of these carbon nanomaterials. In this work, the authors demonstrated an effective plasma exfoliation to prepare graphene, which was particularly suitable for high-performance 
92 supercapacitors. GOs prepared via modified-Hummers method were rapidly exfoliated into

93 graphene or $\mathrm{N}$-doped graphene at low temperatures using a radio frequency dielectric barrier

94 discharge plasma. This study revealed the plasma exfoliation mechanisms by combining optical

95 emission spectroscopy of the plasma discharge with materials microstructure analysis. The

96 promising potential of the plasma exfoliated graphene for EDLCs was confirmed by a variety of

97 electrochemical characterizations.

2. Material and methods

99

\subsection{Preparation of graphite oxides}

100 Graphite oxides were synthesized via modified Hummer`s method[35]. Typically, $2.5 \mathrm{~g}$ graphite

101 (Fisher Scientific) was added into $100 \mathrm{ml}$ concentrated sulfuric acid (98 $w t \%$, Fisher Scientific)

102 and kept stirring at $0{ }^{\circ} \mathrm{C}$ for $4 \mathrm{~h}$. Afterwards $7.5 \mathrm{~g}$ potassium permanganate (Fisher Scientific)

103 was slowly added into above solution before $2.5 \mathrm{~g}$ sodium nitrate (Fisher Scientific) being

104 dissolved. The mixture was continuously stirred for $12 \mathrm{~h}$ and $50 \mathrm{ml}$ distilled water was added

105 into the solution drop by drop under a temperature of $98^{\circ} \mathrm{C}$. Subsequently, $150 \mathrm{ml}$ distilled water

106 was added to further dilute the solution under stirring for $4 \mathrm{~h}$. To reduce the residual

107 permanganate and manganese dioxide to colorless soluble manganese sulfate, 15 ml hydrogen

108 peroxide (30 wt\%, Fisher Scientific) was added. The prepared colloid was transferred into

109 dialysis tubing (14,000 MWCO Daltons, Fisher Scientific) to dialyze in DI water for 2 days.

110 Finally, the dialyzed sample was further separated by centrifugation at 8,000 rpm and washed

111 with DI water till the $\mathrm{pH}$ was close to 7 , and then dried at $60{ }^{\circ} \mathrm{C}$ in a vacuum oven for $24 \mathrm{~h}$. The

112 prepared graphite oxide was denoted in short for GO. 
114 N-modified graphite oxide was prepared by immersing the synthesized GO (2 g) into $2 \mathrm{ml}$

115 pyrrole for $48 \mathrm{~h}$. During that period, the pyrrole spontaneously polymerized and became 116 polypyrrole. The GO sample was subsequently covered with polypyrrole. The polypyrrole117 modified graphite oxide was denoted as GO-PPY.

\subsection{Preparation of graphene}

119 A dielectric barrier discharge plasma system was used to prepare graphene from the GO and GO120 PPY samples. The plasma system (Fig. S1) included a quartz tube that severed as the vacuum 121 chamber, a mechanical vacuum pump, a $13.56 \mathrm{MHz}$ RF power supply, a matching network, a 122 vacuum gauge, and a gas flow controller. Firstly, $300 \mathrm{mg}$ GO or GO-PPY was placed into the 123 quartz tube. Then, the tube was evacuated with the vacuum pump and purged with the process 124 gas (i.e. nitrogen, oxygen, or methane). This step was repeated three times to make sure the 125 residual air in the tube was negligible. After that, the gas flow was adjusted to maintain a stable 126 pressure of $\sim 28$ mTorr. Then the RF power was turned on and the matching network was tuned 127 manually to achieve almost zero watt reflection power. The gas pressure was subsequently 128 increased to 3 Torr and the RF power was gradually increased to $70 \mathrm{~W}$, during which the 129 graphite oxides exfoliated. After the exfoliation (please watch the supplemental video for the 130 exfoliation process), the RF power, gas flow, and vacuum valves were turned off in sequence and 131 the quartz tube was vented to collect the exfoliated sample. Corresponding to the plasma gas, the 132 prepared samples were named as $\mathrm{GO}-\mathrm{O}_{2}, \mathrm{GO}-\mathrm{N}_{2}$, and $\mathrm{GO}-\mathrm{CH}_{4}$. 


\subsection{Preparation of $N$-doped graphene}

$\mathrm{N}$-doped graphene was prepared following the same procedure of the GO samples, but the raw material was GO-PPY. Corresponding to the applied plasma gas, the prepared samples were denoted as GO-PPY-N 2 , GO-PPY-O 2 , and GO-PPY-CH4

\subsection{Preparation of supercapacitor electrodes}

The electrodes were prepared by mixing the graphene samples of $\mathrm{GO}-\mathrm{O}_{2}, \mathrm{GO}-\mathrm{N}_{2}, \mathrm{GO}-\mathrm{CH}_{4}$, GOPPY-N 2 , GO-PPY-O 2 , or GO-PPY-CH $\mathrm{CH}_{4}(80 w t \%)$ with acetylene black $(10 w t \%)$ and PTFE (10 $w t \%$ ), and then pressing onto a nickel foam (EQ-bcnf-16m, MTI Corp.) of $1 \mathrm{~cm}^{2}$ surface area. The electrodes were dried at $60{ }^{\circ} \mathrm{C}$ for 12 hours in an oven. Afterwards, a sandwich structure was formed by placing two pieces of microporous PP separator celgard-3501 between two electrodes in a 2032 type coin cell. Finally, the cell was pressed under a pressure of $1,000 \mathrm{~kg} \mathrm{~cm}^{-2}$ to finish the assembly.

\subsection{Physical characterization}

X-ray photoelectron spectroscopy (XPS) was performed on an SSX-100 system (Surface Science Laboratories, Inc.) equipped with a monochromated $\mathrm{Al} K_{\alpha} \mathrm{X}$-ray source. For high resolution data, the lowest binding energy $\mathrm{C}$ 1s peak was set at $285.0 \mathrm{eV}$ and used as the reference for all of the other elements. Raman spectra were obtained on a Horiba LabRAM confocal Raman microscope system with excitation wavelength of $532 \mathrm{~nm}$ from a diode pumped solidstate laser. A transmission electron microscope (TEM) (JEM-2100 LaB6, JEOL) equipped with energydispersive X-ray spectroscopy (EDX) (Gatan Inc.) was used to study the morphology, microstructure, and elemental mapping of the materials at an acceleration voltage of $200 \mathrm{kV}$. The plasma emission was monitored using an optical spectrometer (USB2000+, Ocean Optics, Inc. USA) 
157 Cyclic voltammetry (CV) and electrochemical impedance spectroscopy (EIS) tests of the 158 supercapacitors were performed on an electrochemical work station (SP-150, BioLogical, France)

159 using $6 \mathrm{~mol} \mathrm{~L}^{-1} \mathrm{KOH}$ electrolyte. The galvanostatic charge/discharge curves were obtained from 160 a battery test system (BTS series, NEWARE, China).

\section{3. Results and discussion}

162 The XRD patterns of GO, GO-N $2, \mathrm{GO}-\mathrm{O}_{2}$ and $\mathrm{GO}-\mathrm{CH}_{4}$ were recorded in Fig. 1. A featured peak 163 located at $\sim 10^{\circ}$ was observed for the GO, which corresponded to the (001) planes of crystalline 164 graphite. On the contrast, the peak at $\sim 10^{\circ}$ vanished after the plasma treatment and a broad peak 165 at $\sim 24^{\circ}$ corresponding to graphitic (002) plane emerged for $\mathrm{GO}-\mathrm{N}_{2}, \mathrm{GO}-\mathrm{O}_{2}$ and $\mathrm{GO}-\mathrm{CH}_{4}$. These 166 results indicated that the pristine GO was successfully exfoliated into disordered and loosely 167 packed graphene [41, 42]. The exfoliation process was also recorded by video. As can be seen, 168 the GO was exfoliated at RF power about $70 \mathrm{~W}$ and gas pressure $\sim 3$ Torr in a short time of a few 169 seconds. In comparison with the tightly stacked GO hard flakes, the plasma treated samples (GO$170 \mathrm{~N}_{2}, \mathrm{GO}-\mathrm{O}_{2}$ and $\mathrm{GO}-\mathrm{CH}_{4}$ ) became flocculent and soft particles with much larger volume (Fig. S2). 


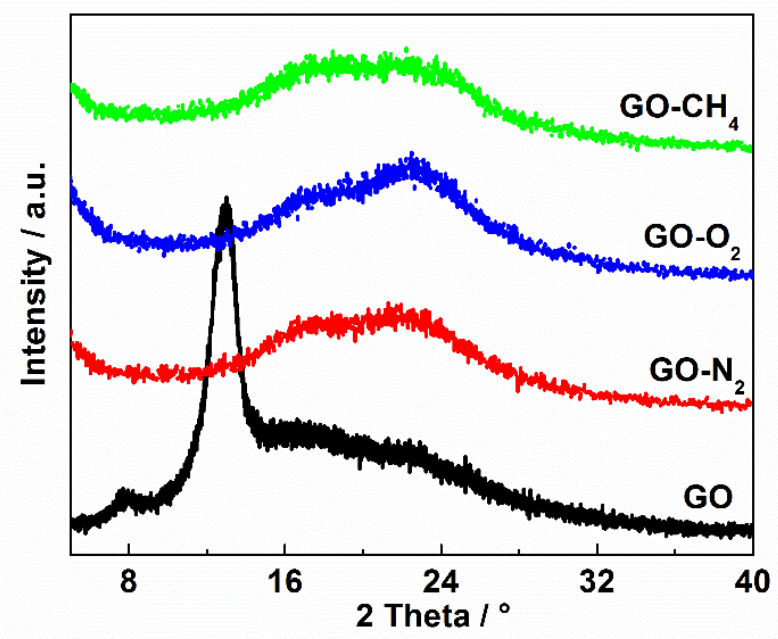

171

Fig. 1 XRD patterns of GO, GO-N $2, \mathrm{GO}-\mathrm{O}_{2}$ and $\mathrm{GO}-\mathrm{CH}_{4}$.

173 Fig. 2 shows the Raman spectra of GO-N ${ }_{2}, \mathrm{GO}-\mathrm{O}_{2}$ and $\mathrm{GO}-\mathrm{CH}_{4}$ in comparison with GO. Two 174 distinct peaks of $D$-band and $G$-band located at $1350 \mathrm{~cm}^{-1}$ and $1580 \mathrm{~cm}^{-1}$, respectively, were 175 displayed. The $D$-band was associated with the $A_{1 g}$ mode breathing vibrations of six member $s p^{2}$ 176 carbon rings, while the $G$-band was attributed to the first order scattering of the stretching 177 vibration mode $E_{2 g}$ observed for the $s p^{2}$ carbon domain [43, 44]. Generally, the intensity ratio of $178 D$-band to $G$ band $\left(I_{D} / I_{G}\right)$ was used to estimate the disorder degree of graphene. The value of $179 I_{D} / I_{G}$ was $1.24,1.32,0.92$ and 0.91 for $\mathrm{GO}, \mathrm{GO}-\mathrm{N}_{2}, \mathrm{GO}-\mathrm{O}_{2}$ and $\mathrm{GO}-\mathrm{CH}_{4}$, respectively. A $I_{D} / I_{G}$ 180 value larger than that of pristine GO implied that more defects were created after the nitrogen 181 plasma treatment $[43,44]$. The smaller $I_{D} / I_{G}$ values for $\mathrm{GO}-\mathrm{O}_{2}$ and $\mathrm{GO}-\mathrm{CH}_{4}$ suggested the 182 removal of oxygen-containing functional groups and partial restoration of the electronic 183 conjugation in graphene sheets by repairing defects [43]. Such a difference most likely arose 184 from the plasma gas during the exfoliation process. 


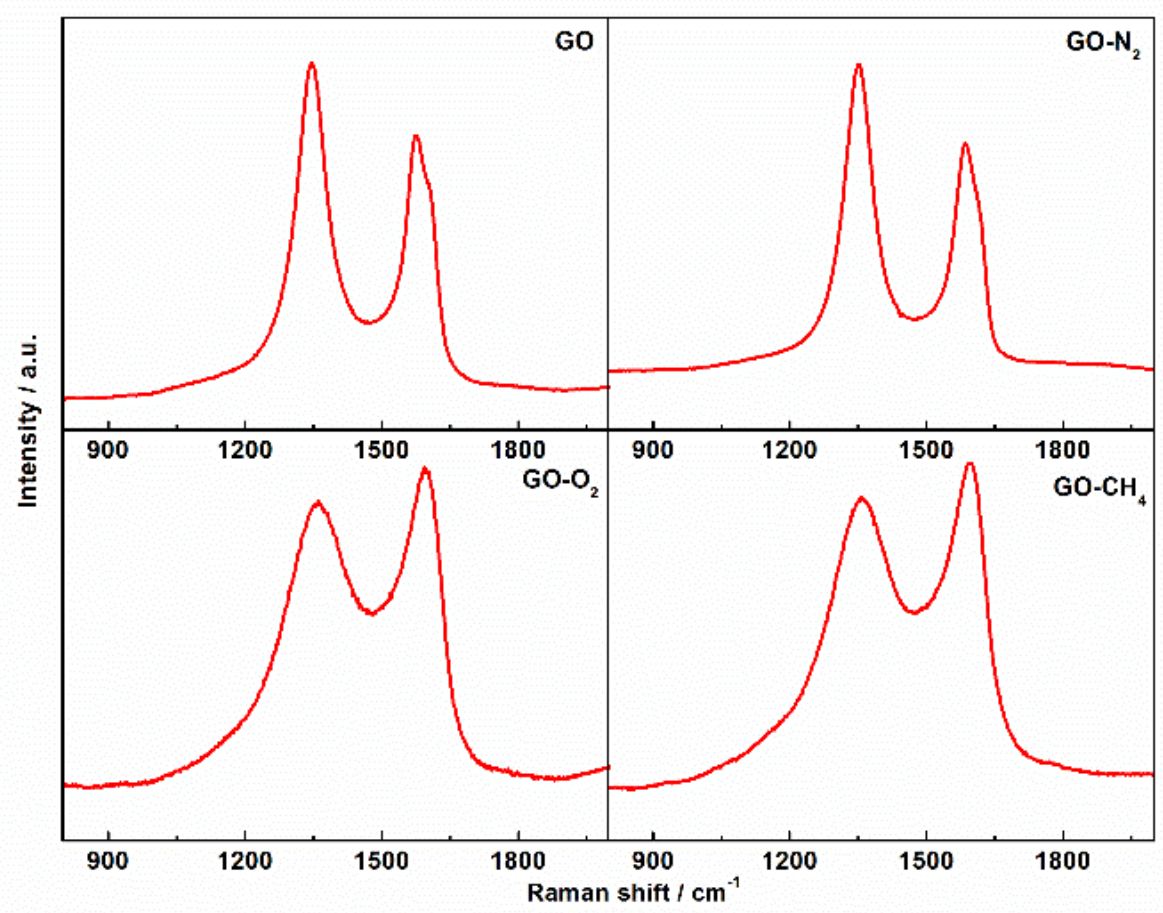

Fig. 2 Raman spectra of $\mathrm{GO}, \mathrm{GO}-\mathrm{N}_{2}, \mathrm{GO}-\mathrm{O}_{2}$ and $\mathrm{GO}-\mathrm{CH}_{4}$.

187 To confirm the morphology and microstructure of the prepared samples, TEM was employed 188 (Fig. 3). As displayed, the treated GO-N $2, \mathrm{GO}-\mathrm{O}_{2}$ and $\mathrm{GO}-\mathrm{CH}_{4}$ samples exhibited ultrathin and 189 flat graphene nanosheets, which were essential to provide beneficial SSA. The TEM results 190 clearly indicated that the RF plasma successfully exfoliated the pristine GO into graphene 191 nanosheets which was in consistence with the XRD analysis. In addition, element mapping (Fig. 192 S3) showed carbon and oxygen uniformly dispersed in these samples. 


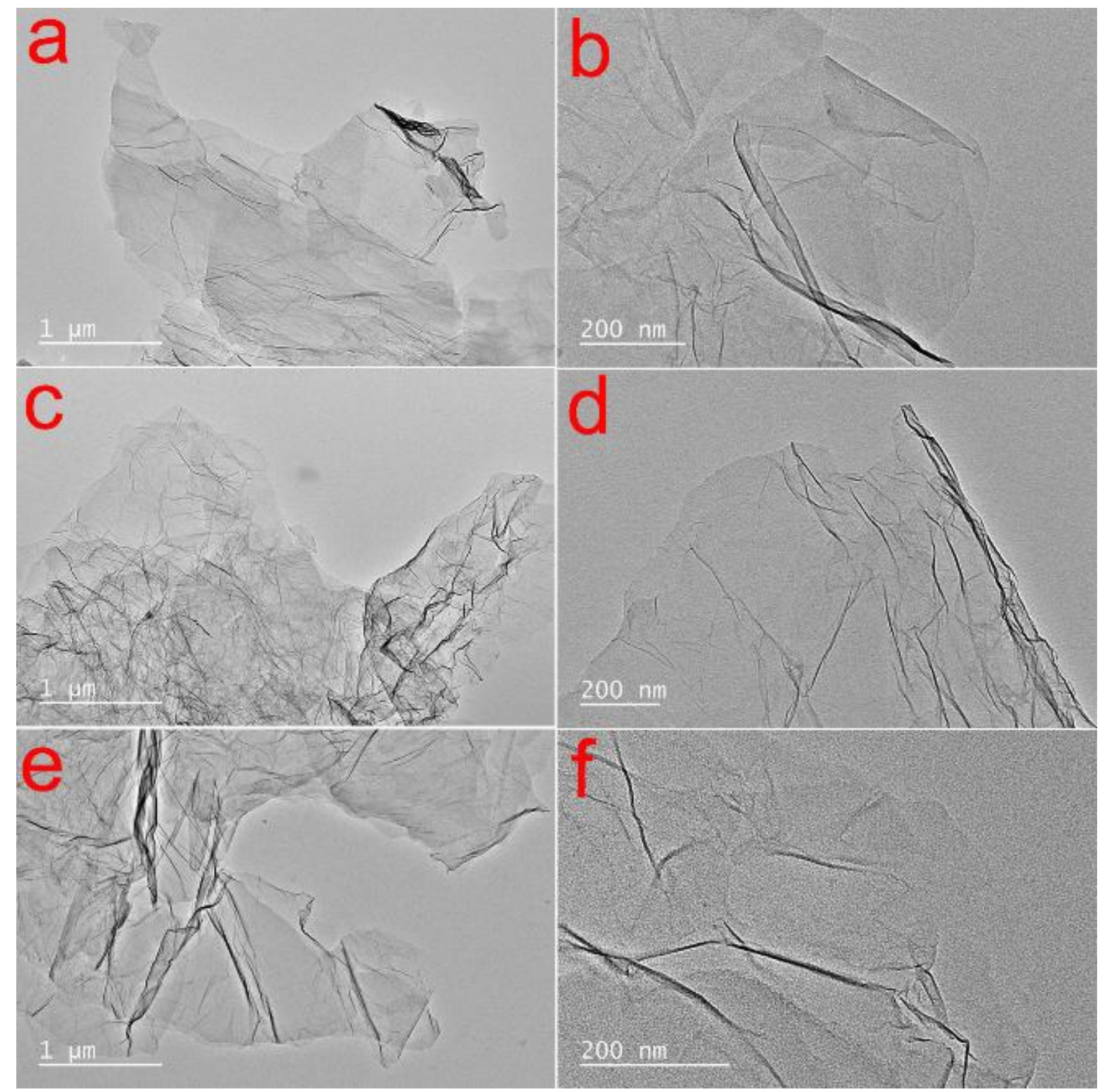

Fig. 3 Different magnifications TEM images of GO-N $2(a, b), \mathrm{GO}_{2} \mathrm{O}_{2}(\mathrm{c}, \mathrm{d})$ and $\mathrm{GO}-\mathrm{CH}_{4}(\mathrm{e}, \mathrm{f})$.

195 To help understand the mechanism of the plasma exfoliation, the process was recorded by video

196 (see Supplementary Information). Interestingly, no matter what kind of gas was used, the color

197 of the plasma turned into bright blue at the very moment of explosion. The blue color was an

198 indication of the presence of oxygen in the plasma. Inspired by this observation, the authors

199 speculated that oxygen might be produced at the moment of explosion. To verify this speculation,

200 optical emission spectra were recorded to study the reactions occurred during the exfoliation.

201 The optical spectra are shown in Fig. 4, which includes the background spectra coming from the 
202 process gases $\left(\mathrm{N}_{2}, \mathrm{O}_{2}\right.$, or $\left.\mathrm{CH}_{4}\right)$. After eliminating the background spectra, it was found that there 203 were three common peaks located at 491.8, 526.8 and $565.9 \mathrm{~nm}$, respectively, for all the three 204 GO samples $\left(\mathrm{GO}-\mathrm{N}_{2}, \mathrm{GO}-\mathrm{O}_{2}\right.$ and $\left.\mathrm{GO}-\mathrm{CH}_{4}\right)$ and $\mathrm{O}_{2}$ plasma background. This result supported the 205 speculation that oxygen was generated during the exfoliation. The suggested interactions 206 between the plasma and the GO sample are as following. In the dielectric barrier discharge, the 207 GO sample was electrically floating in the plasma. Electrons in the plasma moved faster than 208 ions and led to negative self-bias of the GO samples. Ions attracted by the negative potential 209 bombarded the GO and broke the bonds between the oxygen and carbon. Ion-GO interactions 210 also led to localized rapid increase in the temperature of the GO as a result of kinetic energy 211 transfer. Under the assistance of the ion bombardment, the dissociated oxygen species combined 212 to form oxygen molecules between the GO layers. When the RF power and gas pressure were 213 increased to certain levels (e.g. $70 \mathrm{~W}$ and 3 Torr), the thermal expansion of the oxygen gas 214 formed inside the GO led to the separation of the graphite layers and exfoliation occurred. The 215 plasma exfoliation was a swift process; it was completed in just a few seconds. Moreover, the 216 exfoliation did not require external heating. After the process, the surface temperature of the 217 quartz tube was low $80^{\circ} \mathrm{C}$. Comparing with other methods used to prepare graphene (e.g. CVD, 218 PECVD, thermal solvent), RF dielectric barrier discharge plasma was highly efficient. 


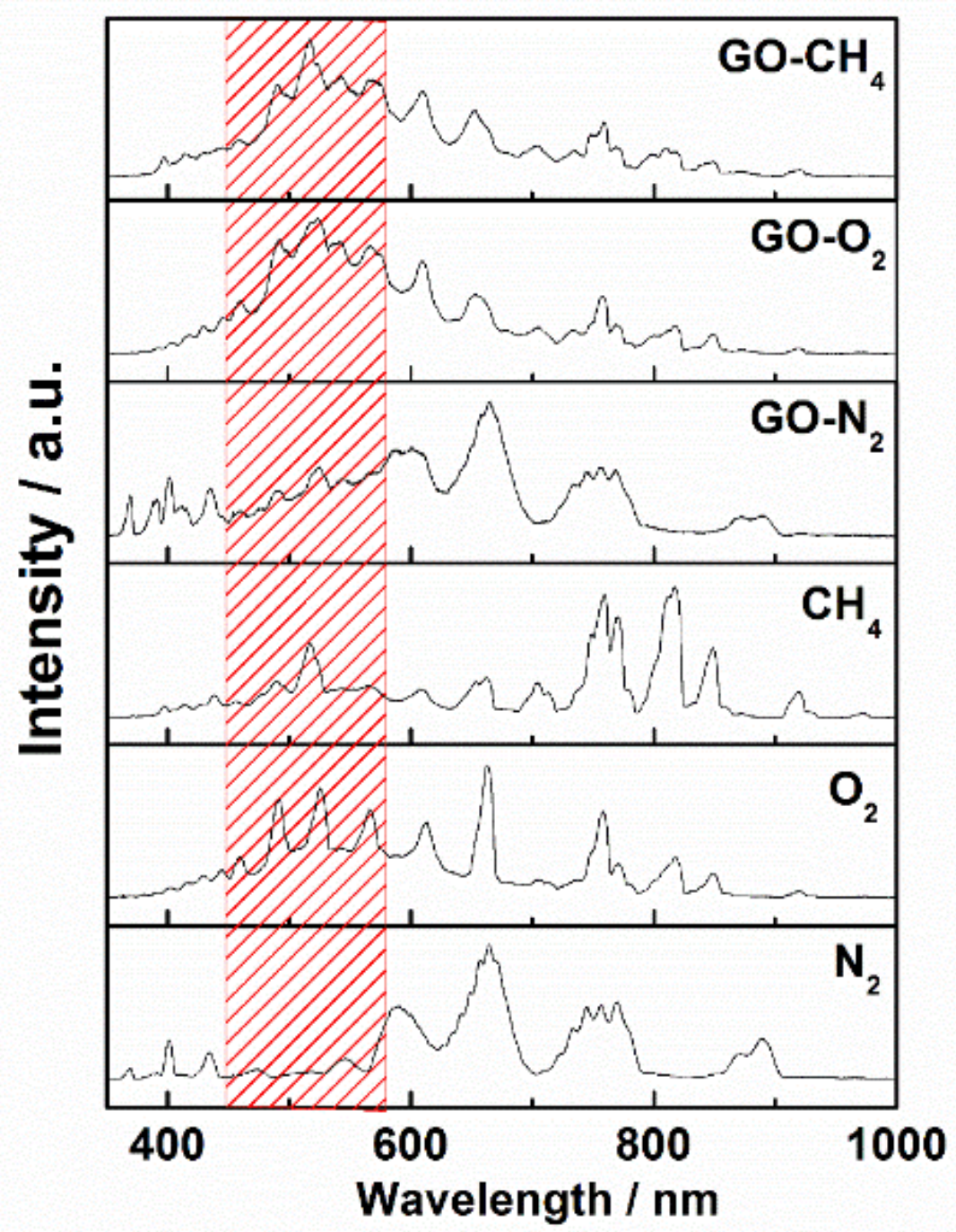

219

Fig. 4 OES observed at the explosion moment for GO-N $2, \mathrm{GO}-\mathrm{O}_{2}$ and $\mathrm{GO}-\mathrm{CH}_{4}$, and the

background.

222 The exfoliated GO was expected to have a porous structure with large surface area. Hence,

223 EDLCs with symmetrical electrodes were prepared to evaluate the specific capacitance of the

224 plasma exfoliated GO. The following equation [45] was used to calculated the specific 225 capacitance: 
227 where $\mathrm{C}$ is the specific capacitance, $I$ is the charge/discharge current, $\Delta t$ is the corresponding 228 charge or discharge time, $m$ is the mass of active materials on single electrode, and $\Delta v$ is the total 229 corresponding potential change.

230 Fig. 5a shows the $\mathrm{CV}$ curves of the electrodes prepared with $\mathrm{GO}-\mathrm{N}_{2}, \mathrm{GO}-\mathrm{O}_{2}$ and GO-CH 4 at a 231 sweep potential window of 0 to $1 \mathrm{~V}$ at a scanning rate of $20 \mathrm{mV} \mathrm{s}^{-1}$. All the three pairs of 232 electrodes exhibited typical rectangular $\mathrm{CV}$ curves with only a little deformation for the $\mathrm{GO}_{-} \mathrm{O}_{2}$ 233 sample, indicating very good EDLCs behavior. At a scanning rate of $20 \mathrm{mV} \mathrm{s}^{-1}$, the specific 234 capacitance of GO-N $2, \mathrm{GO}-\mathrm{O}_{2}$ and $\mathrm{GO}-\mathrm{CH}_{4}$ reached up to 93,178 and $199 \mathrm{~F} \mathrm{~g}^{-1}$, respectively, 235 which indicated the potential of the materials for EDLC applications. In addition, the CV curves 236 of $\mathrm{GO}-\mathrm{N}_{2}, \mathrm{GO}-\mathrm{O}_{2}$ and $\mathrm{GO}-\mathrm{CH}_{4}$ electrodes at different scanning rate ranging from 5 to $200 \mathrm{mV} \mathrm{s}^{-}$ $237{ }^{1}$ were recorded in Fig. S4. With the increase in the scanning rate, the specific capacitance 238 gradually decreased and the shape distortion appeared for all these three electrodes. However, 239 GO- $\mathrm{CH}_{4}$ showed the least distortion. EIS measurements of the supercapacitors were conducted 240 in the frequency range of $10 \mathrm{~Hz}$ to $100 \mathrm{kHz}$ in order to evaluate resistance of the device (Fig. 5b). 241 The EIS consisted of an $x$-intercept at high frequency range, a semicircle in the middle frequency 242 range, and a vertical line in the low frequency range, which corresponded to bulk electrolyte 243 resistance, interfacial impedance between the electrode and bulk solution, and the impedance that 244 was associated with intra-particle pores, respectively [46, 47]. The $\mathrm{GO}-\mathrm{O}_{2}$ sample presented the 245 smallest resistance $(6.6 \Omega)$, while GO-N $\mathrm{N}_{2}(10.2 \Omega)$ and GO- $\mathrm{CH}_{4}(10.0 \Omega)$ showed slightly higher 246 resistance than the $\mathrm{GO}-\mathrm{O}_{2}$, but still small enough for high performance EDLCs electrode 247 material. 

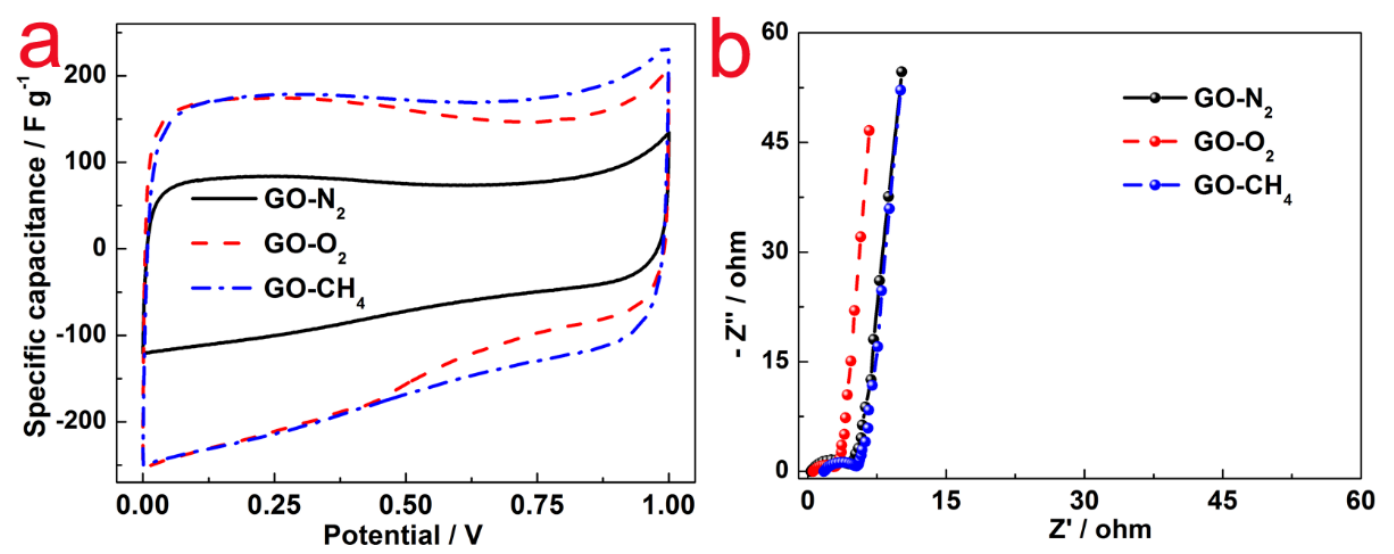

249 Fig. $5 \mathrm{CV}$ curves (a) at scanning rate $20 \mathrm{mV} \mathrm{s}^{-1}$, nyquist plots (b) of GO-N $2, \mathrm{GO}-\mathrm{O}_{2}$ and GO-CH 250 electrodes in $6 \mathrm{~mol} \mathrm{~L}^{-1} \mathrm{KOH}$ electrolyte.

251 The plasma exfoliated GO could be further modified to promote the specific capacitance. It was 252 reported that introducing $\mathrm{N}$ could improve the capacitive performance via pseudocapacitance 253 effect[48]. Therefore, N-modified GO (GO-PPY) was prepared and subsequently exfoliated by 254 plasma.

255 Fig. 6 shows the XRD patterns of GO-PPY, GO-PPY-N 2 , GO-PPY-O 2 and GO-PPY-CH4. After

256 the plasma treatment, the characteristic peak of GO located at $\sim 10^{\circ}(001)$ disappeared, but a 257 broad peak around $24^{\circ}(002)$ showed up, suggesting that the GOs were successfully exfoliated 258 into graphene by the plasmas. Likewise, the same phenomenon as GO exfoliation was observed 259 for GO-PPY with each of the plasma gases. 


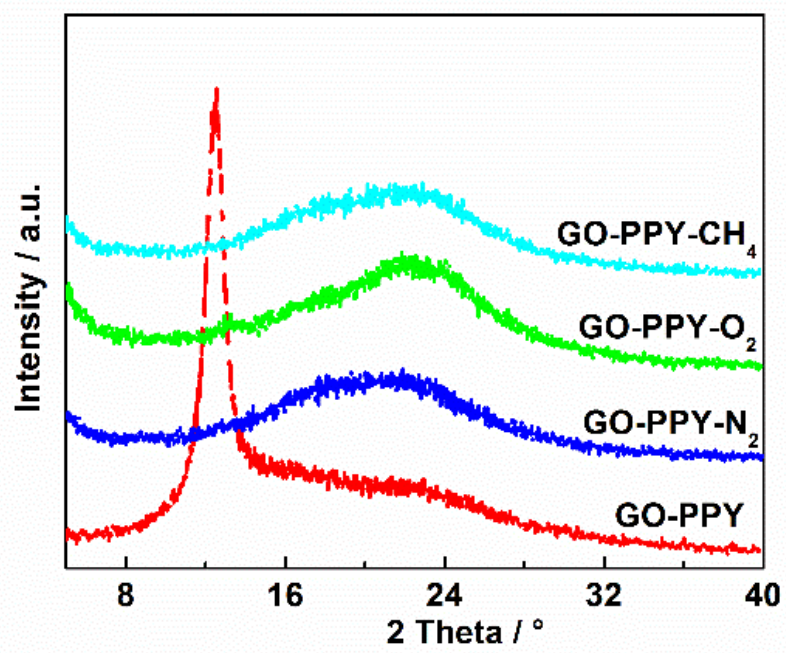

Fig. S5 illustrated Raman spectra of GO, GO-PPY-N 2 , GO-PPY-O 2 and GO-PPY-CH 4 . Two

264 distinct peaks of $D$-band and $G$-band located at $1350 \mathrm{~cm}^{-1}$ and $1580 \mathrm{~cm}^{-1}$, respectively, were 265 observed, which were related to $A_{1 g}$ mode breathing vibrations of six member $s p^{2}$ carbon rings, 266 and the first order scattering of the stretching vibration mode $E_{2 g}$ of the $s p^{2}$ carbon domain [43, 267 44], respectively. The intensity ratio of $D$-band to $G$ band $\left(I_{D} / I_{G}\right)$ was also used to estimate the 268 disorder degree of graphene. The value of $I_{D} / I_{G}$ was $1.24,0.92,0.98$ and 0.86 for GO, GO-PPY$269 \mathrm{~N}_{2}, \mathrm{GO}-\mathrm{PPY}-\mathrm{O}_{2}$ and GO-PPY- $\mathrm{CH}_{4}$, respectively, suggesting the removal of oxygen-containing 270 functional groups and the partial restoration of the electronic conjugation in graphene sheets by 271 repairing the defects [43].

272 To verify the microstructure of the prepared N-doped graphene, TEM was conducted (Fig. 7). As 273 shown in Fig. 7 and Fig. S6, two-dimensional ultrathin graphene monolayer or multilayers were 274 observed with some ripples. In addition, the existence of monolayer graphene for GO-PPY-CH 275 was further proved by SAED (the inset in Fig. 7d). A perfect hexagonal pattern was presented, 
which confirmed the well-crystallized single layer graphene structure[48, 49]. Elemental 277 mapping (Fig. S7) was made to verify the nitrogen inclusion. The signals of carbon, oxygen and

278 nitrogen were all detected and distributed uniformly, indicating nitrogen was successfully 279 introduced. In other word, the N-doped graphene was expected to be a suitable material for high 280 performance EDLCs.

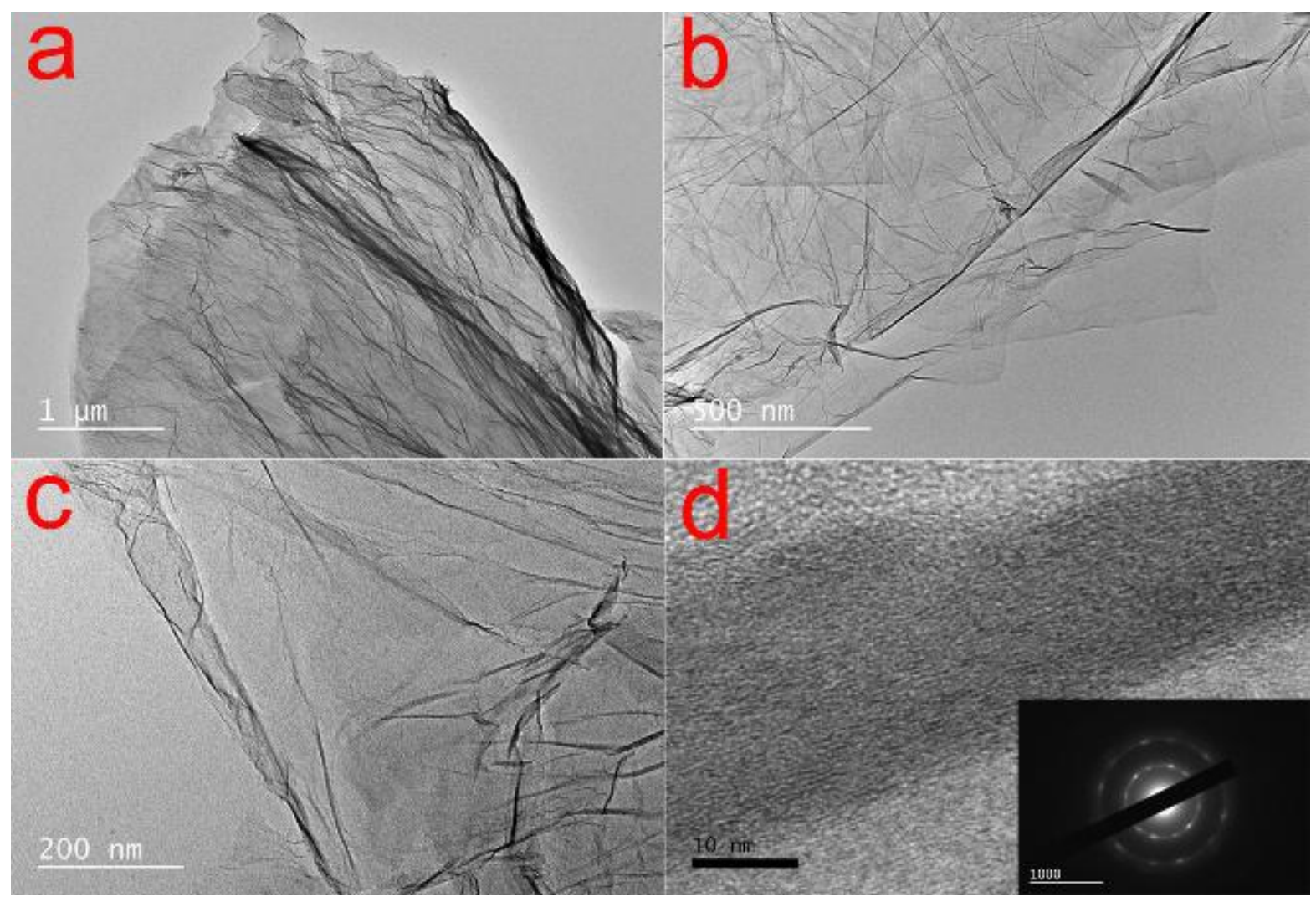

282 Fig. 7 TEM images of GO-PPY-CH 4 under different magnifications. The inset in (d) is SAED.

283 During the plasma exfoliation, OESs were recorded (Fig. S8). Interestingly, the same bright blue 284 light appeared at the explosion moment for all the three gases. Besides, the featured peaks of 285 oxygen located at 491.8, 526.8 and $565.9 \mathrm{~nm}$ were also observed. All these results revealed that 286 the exfoliation mechanisms were similar to that of GO, the only difference was that $\mathrm{N}$ was 287 incorporated in the treated sample. 
288 XPS analysis was employed to analyze the functional groups in the surface of GO-PPY-N 2 , GO289 PPY-O ${ }_{2}$ and GO-PPY-CH4. In Fig. 8a, signals of C 1s $(532 \mathrm{eV}), \mathrm{O}$ 1s $(284 \mathrm{eV})$ and N $1 \mathrm{~s}(400 \mathrm{eV})$ 290 were detected, which indicated that $\mathrm{N}$ was successfully introduced into the prepared graphene. 291 The XPS analysis also verified the results of TEM elemental mapping. High resolution O 1s 292 spectrum (Fig. 8b and Fig. S9a, c) was deconvoluted into three peaks at binding energy 293 of ca. $531 \mathrm{eV}, 532 \mathrm{eV}$, and $533.5 \mathrm{eV}$, which were assigned to O-I, O-II and O-III, respectively. 294 The three $\mathrm{O}$ species represented $\mathrm{C}=\mathrm{O}$ groups for $\mathrm{O}-\mathrm{I}, \mathrm{C}-\mathrm{OH}$ groups and/or C-O-C groups for O295 II, and O-C=O groups for O-III, respectively[50, 51]. Among them, O-I and O-II were the 296 dominant functionalities that would contribute to the pseudocapacitance through the 297 quinone/hydroquinone redox [50]. Besides, two peaks were detected at binding energy ca.398.9 298 and $401.0 \mathrm{eV}$ for $\mathrm{N}$ species, which were attributed to pyridinic-N, and quaternary- $\mathrm{N}$, respectively 299 (Fig. 8c and Fig. S9b, d) [52, 53]. The significance of introducing $\mathrm{N}$ was that pyridinic-N could 300 lead to great pseudocapacitance effect and improve the conductivity, resulting in enhanced 301 capacitive performance. In addition, atomic element concentrations in the prepared GO-PPY, 302 GO-PPY-N 2 , GO-PPY-O 2 and GO-PPY-CH 4 were summarized in Table 1. It was noted that GO303 PPY possessed the highest atomic content of nitrogen (10.9\%), which was reasonable due to the 304 incorporation of polypyrrole before the plasma treatment. After exfoliation, 8.9\%, 1.1\% and $4.2 \%$ $305 \mathrm{~N}$ was detected in GO-PPY-N $2, \mathrm{GO}-\mathrm{PPY}-\mathrm{O}_{2}$ and GO-PPY- $\mathrm{CH}_{4}$, respectively. This result 306 indicated that $\mathrm{N}$ was partially removed due to the interactions between the plasma species and 307 polypyrrole. Oxygen was most effective in removing polypyrrole. Further studied are underway 308 to reveal the chemical interactions between the plasma species and GO-PPY. 

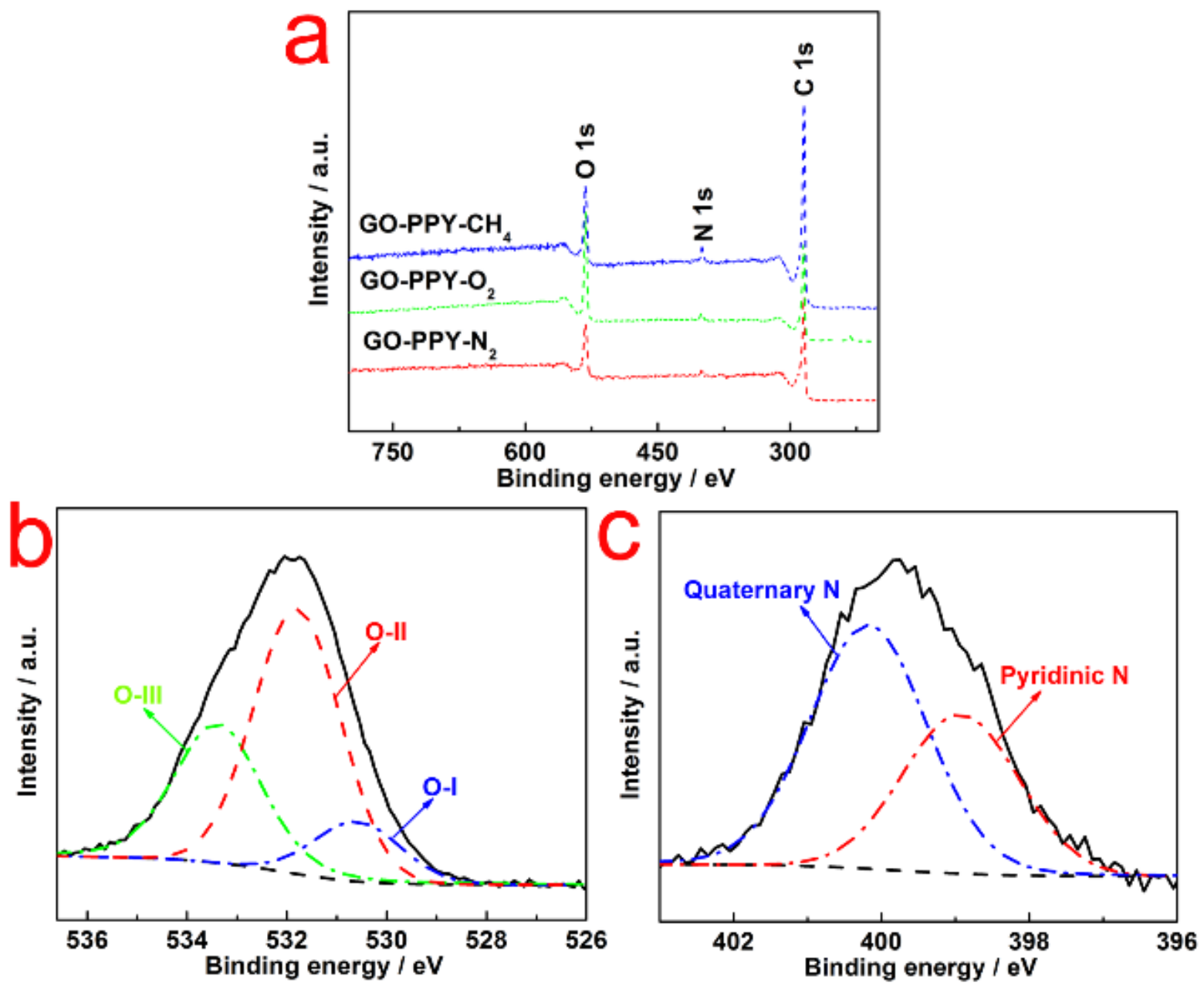

Fig. 8 XPS survey (a) of GO-PPY-N 2 , GO-PPY-O ${ }_{2}$ and GO-PPY-CH 4 and high resolution $\mathrm{O}$ 1s

312 Table. 1 Atomic elements content of prepared GO-PPY, GO-PPY-N 2, GO-PPY-O 2 and GO313 PPY-CH4.

\begin{tabular}{cccc}
\hline & $\begin{array}{c}\text { Carbon } \\
(\text { Atomic } \%)\end{array}$ & $\begin{array}{c}\text { Oxygen } \\
\text { (Atomic } \%)\end{array}$ & $\begin{array}{c}\text { Nitrogen } \\
\text { (Atomic \%) }\end{array}$ \\
\hline GO-PPY & 73.3 & 15.7 & 10.9 \\
GO-PPY-N & 73.8 & 17.4 & 8.9 \\
GO-PPY-O & 86.7 & 12.2 & 1.1 \\
GO-PPY-CH & 81.4 & 14.5 & 4.2 \\
\hline
\end{tabular}

(b) and N 1s (c) XPS spectra of GO-PPY- $\mathrm{CH}_{4}$.

315 EDLCs were prepared with the exfoliated N-doped graphene as the electrode materials. CV tests 316 were conducted to evaluate the electrochemical performance. Fig.9a shows the CV curves of 
317 GO-PPY-N 2 , GO-PPY-O ${ }_{2}$ and GO-PPY- $-\mathrm{CH}_{4}$ electrodes in $6 \mathrm{~mol} \mathrm{~L}^{-1} \mathrm{KOH}$ electrolyte at a 318 scanning rate of $20 \mathrm{mV} \mathrm{s}^{-1}$. All three cells exhibited characteristic rectangular shape CV curves, 319 which were an indication of very good electrochemical EDLC behavior. The specific capacitance 320 was calculated according to formula (1) to quantify the EDLCs' performance. The specific 321 capacitance reached up to 130,178 and $250 \mathrm{~F} \mathrm{~g}^{-1}$ for GO-PPY-N 2 , GO-PPY-O ${ }_{2}$ and GO-PPY$322 \mathrm{CH}_{4}$, respectively. Although GO-PPY-N 2 contained the highest concentration of $\mathrm{N}$ from the XPS 323 analysis, it produced the lowest specific capacitance. This result implied that only certain type of 324 nitrogen doping, i.e. pyridinic-N, was effective in promoting the capacitive performance. $\mathrm{CH}_{4}$ 325 plasma promoted the incorporation of effective $\mathrm{N}$ in $\mathrm{GO}$ and/or created additional surface 326 structures and functional groups that beneficial the capacitive performance. In addition, the better 327 capacitance performance of GO-PPY-CH 4 may be arisen from two distinct effects of $\mathrm{CH}_{4}$ plasma: 328 i) hydrogen plasma etching of the graphite oxides, and ii) growth of nanostructured carbon on the 329 produced graphene. These effects created defects and active surface that promoted the 330 capacitance performance.

331 The impedance spectra were measured over a frequency range from $100 \mathrm{kHz}$ to $10 \mathrm{~Hz}$ (Fig. 9). 332 From the inset, a short $x$-intercept, small diameter of the semicircle, and high slope at low 333 frequency revealed that the GO-PPY- $\mathrm{CH}_{4}$ electrodes had small bulk electrolyte resistance, 334 interfacial impedance and the inter-particle ionic impedance. A smaller resistance meant higher 335 conductivity and less energy loss, as well as good performance of EDLCs. 
336

337
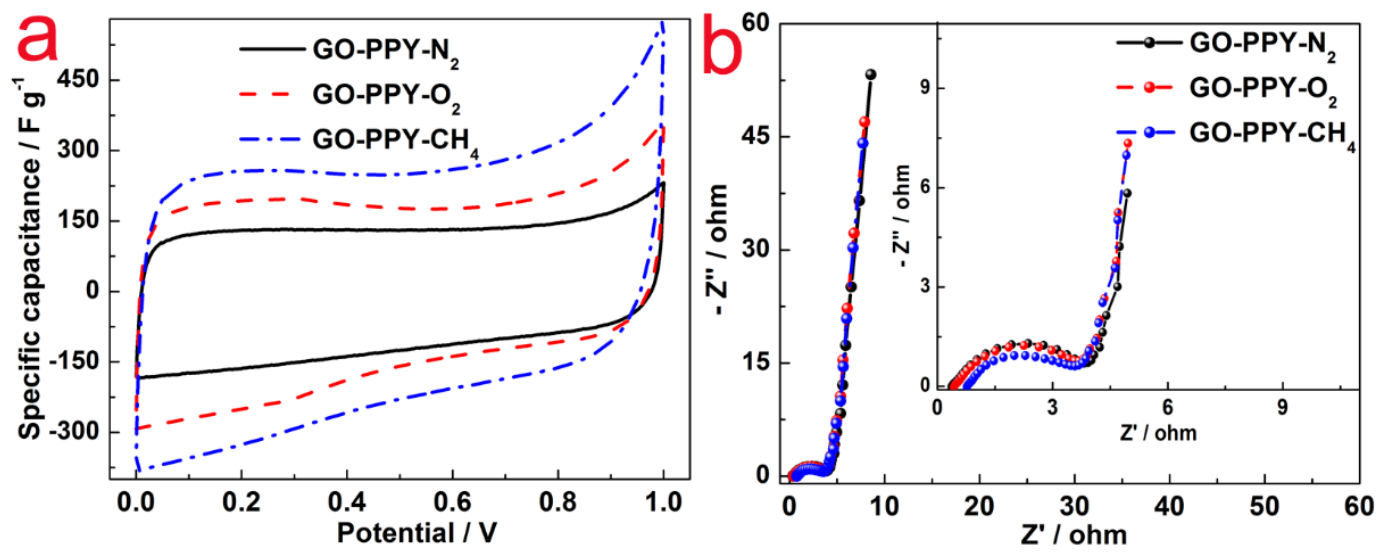

Fig. $9 \mathrm{CV}$ curves (a) at scanning rate $20 \mathrm{mV} \mathrm{s}^{-1}$, nyquist plots (b) of GO-PPY-N 2 , GO-PPY-O and GO-PPY-CH 4 electrodes in $6 \mathrm{~mol} \mathrm{~L}^{-1} \mathrm{KOH}$ electrolyte; The inset in (b) shows the magnified view of the high-frequency region.

The specific capacitance was also recorded at different scanning rate ranging from 5 to $200 \mathrm{mV}$ $\mathrm{s}^{-1}$ in $\mathrm{CV}$ test for all three samples (Fig. 9a and Fig. S10). GO-PPY-CH 4 showed much higher specific capacitance and rate capability with negligible distortion in comparison with that of GOPPY-N 2 and GO-PPY-O ${ }_{2}$.

Meanwhile, as another important index for EDLCs, stability or cycle life of GO-PPY-CH 4 was assessed by charge/discharge at various current densities. In galvanostatic charge/discharge measurement, symmetric lines without $I R_{d r o p}$ indicated a good capacitive behavior of EDLCs, which was consistent with the result of CV measurement. The cycling performance of GO-PPY$\mathrm{CH}_{4}$ electrode was also evaluated using the galvanostatic charge/discharge shown in Fig. $10 \mathrm{~b}$. The measurement yielded a specific capacitance as high as $312 \mathrm{~F} \mathrm{~g}^{-1}$ at beginning and ended at $250 \mathrm{~F} \mathrm{~g}^{-1}$ under $0.1 \mathrm{~A} \mathrm{~g}^{-1}$ charge/discharge current with little fluctuation. The specific capacitance remained at $220,215,196,178 \mathrm{~F} \mathrm{~g}^{-1}$ with a retention of almost $100 \%$ after 1000 consecutive cycles under larger currents of $0.5,1.0,5.0$ and 10.0 $\mathrm{A} \mathrm{g}^{-1}$, respectively. The results indicated that the electrodes were highly reversible during charge/discharge processes. 

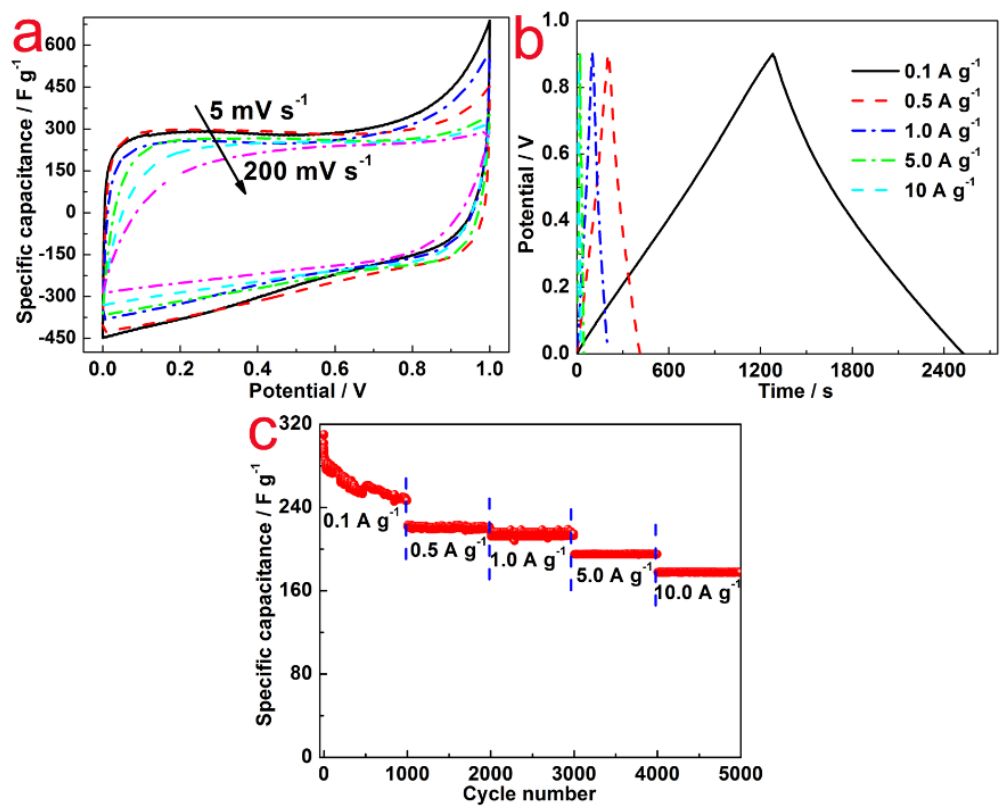

Fig. $10 \mathrm{CV}$ curves (a) at various scanning rates ranging from 5 to $200 \mathrm{mV} \mathrm{s}^{-1}$, galvanostatic

charge/discharge curves (b) and cycle life plot (c) at different current density ranging from 0.1 to $10 \mathrm{~A} \mathrm{~g}^{-1}$ for GO-PPY-CH 4 electrodes in $6 \mathrm{~mol} \mathrm{~L}^{-1} \mathrm{KOH}$ electrolyte, respectively.

\section{Conclusion}

359 Graphite oxides were successfully exfoliated into graphene and N-doped graphene using radio360 frequency dielectric barrier discharge plasma. The plasma exfoliation required a certain power 361 level and pressure to transfer sufficient energy. Optical emission spectroscopy revealed the 362 mechanisms of plasma exfoliation, which was due to the breakage of the C-O bonds and 363 combination of $\mathrm{O}$ atoms into molecules that expanded under plasma. Comparing with oxygen 364 and nitrogen plasmas, $\mathrm{CH}_{4}$ plasma exfoliated $\mathrm{N}$-doped graphene exhibited better capacitive 365 characteristics, including high specific capacitance $\sim 312 \mathrm{~F} \mathrm{~g}^{-1}$ and stable charge/discharge 366 performance. The RF plasma exfoliation was a low-temperature and efficient approach to 367 manufacturing graphene. 
This research was funded by: 1) China Scholarship Council; 2) NSF MRI award \#1427888; 3) NSF EPSCoR Track II Dakota BioCon Center \#1330840; 4) NSF award \#1462389; 5) NSF award \#1536209; 6) North Central Regional Sun Grant Center at South Dakota State University through a grant provided by the US Department of Energy Bioenergy Technologies Office under award number DE-FG36-08GO88073.

\section{References}

[1] H.-P. Cong, X.-C. Ren, P. Wang, S.-H. Yu, Energy Environ. Sci. 6 (2013) 1185-1191.

[2] Y. Zhu, S. Murali, M.D. Stoller, K. Ganesh, W. Cai, P.J. Ferreira, A. Pirkle, R.M. Wallace, K.A. Cychosz, M. Thommes, Science 332 (2011) 1537-1541.

[3] C. Guan, X. Xia, N. Meng, Z. Zeng, X. Cao, C. Soci, H. Zhang, H.J. Fan, Energy Environ. Sci. 5 (2012) 9085-9090.

[4] Y.Y. Wang, B.H. Hou, H.Y. Lü, C.L. Lü, X.L. Wu, ChemistrySelect 1 (2016) 1441-1447.

[5] D. Puthusseri, V. Aravindan, S. Madhavi, S. Ogale, Energy Environ. Sci. 7 (2014) 728-735.

[6] C. Xiang, M. Li, M. Zhi, A. Manivannan, N. Wu, J. Power Sources 226 (2013) 65-70.

[7] W. Zhou, X. Cao, Z. Zeng, W. Shi, Y. Zhu, Q. Yan, H. Liu, J. Wang, H. Zhang, Energy Environ. Sci. 6 (2013) 2216-2221.

[8] S.-I. Kim, J.-S. Lee, H.-J. Ahn, H.-K. Song, J.-H. Jang, ACS Appl. Mater. Interfaces 5 (2013) 1596-1603.

[9] Z. Lei, J. Zhang, X. Zhao, J. Mater. Chem. 22 (2012) 153-160.

[10] C. Lei, N. Amini, F. Markoulidis, P. Wilson, S. Tennison, C. Lekakou, J. Mater. Chem. A, 1 (2013) 6037-6042.

[11] T. Kim, G. Jung, S. Yoo, K.S. Suh, R.S. Ruoff, ACS Nano 7 (2013) 6899-6905.

[12] K. Wang, Y. Cao, Z. Gu, P. Ahrenkiel, J. Lee, Q.H. Fan, RSC Adv. 6 (2016) 26738-26744. 
392 [13] K. Jost, D. Stenger, C.R. Perez, J.K. McDonough, K. Lian, Y. Gogotsi, G. Dion, Energy 393 Environ. Sci. 6 (2013) 2698-2705.

394 [14] A. Borenstien, M. Noked, S. Okashy, D. Aurbach, J. Electrochem. Soc. 160 (2013) A1282395 A1285.

396 [15] A. Pandolfo, A. Hollenkamp, J. Power Sources 157 (2006) 11-27.

397 [16] Q. Cheng, J. Tang, J. Ma, H. Zhang, N. Shinya, L.-C. Qin, Phys. Chem. Chem. Phys. 13 398 (2011) 17615-17624.

399 [17] Q. Wu, Y. Xu, Z. Yao, A. Liu, G. Shi, ACS Nano 4 (2010) 1963-1970.

400 [18] J. Zhang, J. Jiang, H. Li, X. Zhao, Energy Environ. Sci. 4 (2011) 4009-4015.

401 [19] C. Lee, X. Wei, J.W. Kysar, J. Hone, Science 321 (2008) 385-388.

402 [20] L.A. Jauregui, Y. Yue, A.N. Sidorov, J. Hu, Q. Yu, G. Lopez, R. Jalilian, D.K. Benjamin, 403 D.A. Delkd, W. Wu, Ecs Trans. 28 (2010) 73-83.

404 [21] L.L. Zhang, R. Zhou, X. Zhao, J. Mater. Chem. 20 (2010) 5983-5992.

405 [22] M. Pumera, Chem. Rec. 9 (2009) 211-223.

406 [23] Y. Zhu, S. Murali, W. Cai, X. Li, J.W. Suk, J.R. Potts, R.S. Ruoff, Adv. Mater. 22 (2010) $407 \quad 3906-3924$.

408 [24] L.-S. Zhang, L.-Y. Jiang, H.-J. Yan, W.D. Wang, W. Wang, W.-G. Song, Y.-G. Guo, L.-J. 409 Wan, J. Mater. Chem. 20 (2010) 5462-5467.

410 [25] X. Wang, L. Zhi, K. Müllen, Nano Lett. 8 (2008) 323-327.

411 [26] L. Qu, Y. Liu, J.-B. Baek, L. Dai, ACS Nano 4 (2010) 1321-1326.

412 [27] C. Liu, Z. Yu, D. Neff, A. Zhamu, B.Z. Jang, Nano Lett. 10 (2010) 4863-4868.

413 [28] X. Yang, X. Zhang, Y. Ma, Y. Huang, Y. Wang, Y. Chen, J. Mater. Chem. 19 (2009) 27104142714. 
415

416

417

418

419

420

421

422

423

424

425

426

427

428

429

430

431

432

433

434

435

436

437

[29] B. Zhang, Q. Li, T. Cui, Biosens. Bio. 31 (2012) 105-109.

[30] Z. Chen, Y.-M. Lin, M.J. Rooks, P. Avouris, Phys. E 40 (2007) 228-232.

[31] K.S. Novoselov, A.K. Geim, S. Morozov, D. Jiang, Y. Zhang, S.a. Dubonos, I. Grigorieva, A. Firsov, Science 306 (2004) 666-669.

[32] P.R. Somani, S.P. Somani, M. Umeno, Chem. Phys. Lett. 430 (2006) 56-59.

[33] H. Huang, W. Chen, S. Chen, A.T.S. Wee, ACS Nano 2 (2008) 2513-2518.

[34] H. Wang, J.T. Robinson, X. Li, H. Dai, J. Am. Chem. Soc. 131 (2009) 9910-9911.

[35] W.S. Hummers Jr, R.E. Offeman, J. Am. Chem. Soc. 80 (1958) 1339-1339.

[36] Y. Qiu, X. Zhang, S. Yang, Phys. Chem. Chem. Phys. 13 (2011) 12554-12558.

[37] H.M. Jeong, J.W. Lee, W.H. Shin, Y.J. Choi, H.J. Shin, J.K. Kang, J.W. Choi, Nano Lett. $11(2011)$ 2472-2477.

[38] B. You, L. Wang, L. Yao, J. Yang, Chem. Commun. 49 (2013) 5016-5018.

[39] Y. Lu, F. Zhang, T. Zhang, K. Leng, L. Zhang, X. Yang, Y. Ma, Y. Huang, M. Zhang, Y. Chen, Carbon 63 (2013) 508-516.

[40] E. Haque, M.M. Islam, E. Pourazadi, M. Hassan, S.N. Faisal, A.K. Roy, K. Konstantinov, A.T. Harris, A.I. Minett, V.G. Gomes, RSC Adv. 5 (2015) 30679-30686.

[41] L. Stobinski, B. Lesiak, A. Malolepszy, M. Mazurkiewicz, B. Mierzwa, J. Zemek, P. Jiricek, I. Bieloshapka, J. Electron Spectros. Relat. Phenom. 195 (2014) 145-154.

[42] Y. Han, Y. Wu, M. Shen, X. Huang, J. Zhu, X. Zhang, J. Mater. Sci. 48 (2013) 4214-4222.

[43] J. Yan, J. Liu, Z. Fan, T. Wei, L. Zhang, Carbon 50 (2012) 2179-2188.

[44] F.M. Hassan, V. Chabot, J. Li, B.K. Kim, L. Ricardez-Sandoval, A. Yu, J. Mater. Chem. A, 1 (2013) 2904-2912.

[45] M. Wahid, G. Parte, D. Phase, S. Ogale, J. Mater. Chem. A 3 (2015) 1208-1215. 
[46] H.D. Yoo, J.H. Jang, J.H. Ryu, Y. Park, S.M. Oh, J. Power Sources 267 (2014) 411-420.

[47] Y. Mun, C. Jo, T. Hyeon, J. Lee, K.-S. Ha, K.-W. Jun, S.-H. Lee, S.-W. Hong, H.I. Lee, S. Yoon, Carbon 64 (2013) 391-402.

[48] W. Si, J. Zhou, S. Zhang, S. Li, W. Xing, S. Zhuo, Electrochim. Acta 107 (2013) 397-405.

[49] J.N. Coleman, Acc. Chem. Res. 46 (2012) 14-22.

[50] Z. Li, Z. Xu, H. Wang, J. Ding, B. Zahiri, C.M. Holt, X. Tan, D. Mitlin, Energy Environ. Sci. 7 (2014) 1708-1718.

[51] C. Wang, L. Sun, Y. Zhou, P. Wan, X. Zhang, J. Qiu, Carbon 59 (2013) 537-546.

[52] W.-h. Lee, J.H. Moon, ACS Appl. Mater. Interfaces 6 (2014) 13968-13976.

[53] M. Sevilla, L. Yu, L. Zhao, C.O. Ania, M.-M. Titiricic, ACS Sustainable Chem. Eng. 2 (2014) 1049-1055.

\section{Biography}

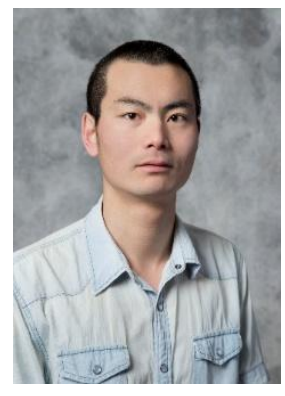

Keliang Wang received his B. S and M. S. degrees in Chemical Engineering from Northwest Normal University in 2011 and 2014, respectively. Currently, he is a Ph. D. candidate in Biological Science at South Dakota State University. His research interest is focused on fuel cells, supercapacitors and batteries.

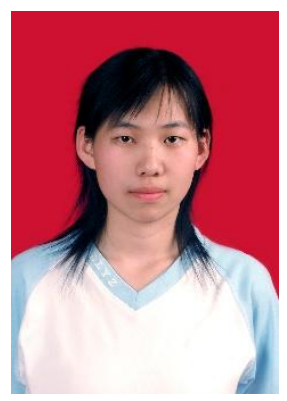

Ming Xu received her B. S degree in Chemical Engineering from Northwest Normal University in 2011. Currently, she works as an engineer in PetroChina Lanzhou Petrochemical Company. Her research interest is focused on supercapacitors and batteries.

Yan Gu received her B. S and M. S. degrees in Chemical Engineering from Nanjing University of Forest in 2001 and 2004, respectively. Ms. Gu is Research Scientist in Institute of Chemical Industry of Forest Products 
(Nanjing, China). Her research interest is focused on porous materials characterization.

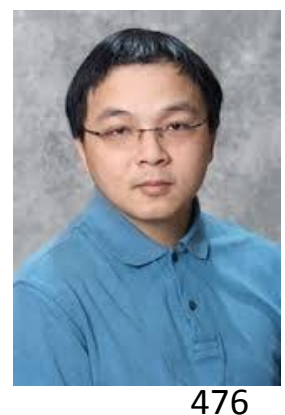

Dr. Zhengrong Gu received his $\mathrm{Ph}$. D in Chemical Engineering from Iowa State University. Dr. Gu is Associate Professor in Agricultural and Biosystems Engineering at South Dakota State University. Dr. Gu's research interest focuses on synthesis of functional carbon nanomaterials for applications, such as energy storage, catalysis, separation, bio-sensing and biomedical therapy.

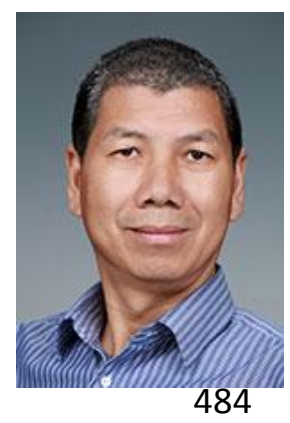

Dr. Jun Liu received his $\mathrm{Ph}$. D. in Materials Science and Engineering from the University of Washington. Currently, Dr. Liu serves as Director of the Energy Processes and Materials Division within Pacific Northwest National Laboratory's Energy and Environment Directorate since March 2013. His main research interest includes synthesis of functional nanomaterials for energy storage, catalysis, environmental separation and health care. So far, Dr. Liu has published more than 350 peer reviewed publications and received more than 55 U.S. patents.

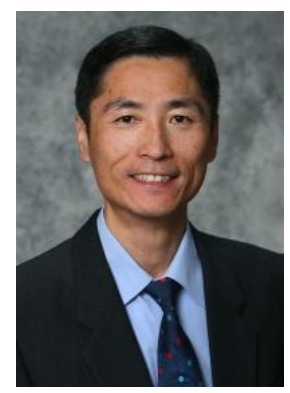

Dr. Qi Hua Fan received his Ph. D. in applied physics from the University of Aveiro. He is currently an Associate Professor at Michigan State University. Dr. Fan's research interest includes plasma sources for large-area coatings and plasma processing of nanostructured materials for energy harvesting, energy storage, and electro-optical devices. 

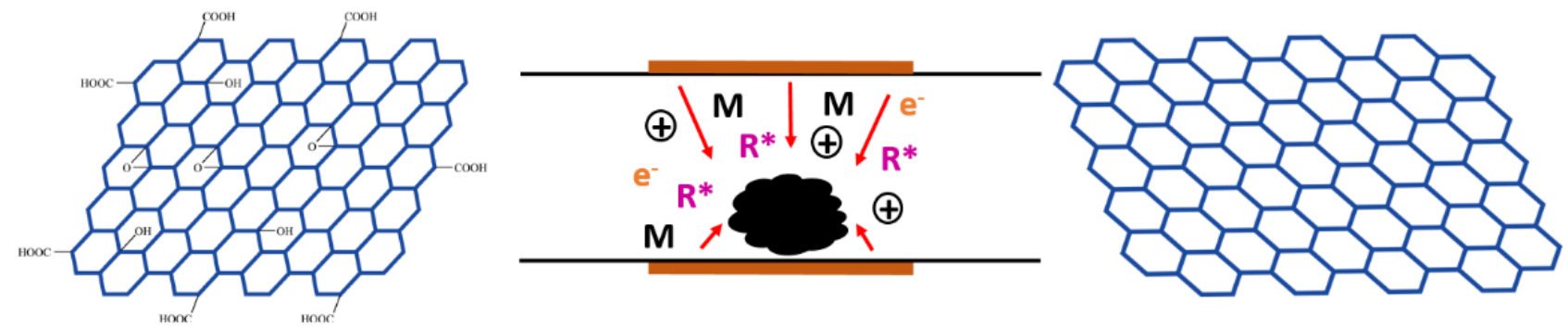

M: molecular $\quad R^{*}$ : free radical $\quad$ ( : ions $\quad e^{-:}$electrons 